\title{
ANALISIS POTENSI, EFEKTIFITAS DAN KONTRIBUSI PAJAK HOTEL TERHADAP PENDAPATAN ASLI DAERAH KABUPATEN TANA TORAJA
}

\author{
Hesty Reny Tonapa ${ }^{1}$, David Saerang ${ }^{2}$, Lidia Mawikere $^{3}$ \\ 1.2.3 Fakultas Ekonomi dan Bisnis, Jurusan Akuntansi, Universitas Sam Ratulangi, J1. Kampus Bahu, Manado, \\ 95115, Indonesia \\ E-mail : hestyreny@gmail.com
}

\begin{abstract}
The purpose of this study was to calculate how much is the potential, the effectiveness and contributions of Hotel taxes in Tana Toraja as one of the source of regional revenue. This research is using descriptive method by analyzing the realization data of hotel Taxes in 20112015. The results showed that the potential of hotel taxes has not been achieved optimally because the actual revenues still well below its potential and the difference between the actual and potential of hotel taxes reached Rp. 891,981,757 in 2015. The results of this study also shows that the effectiveness of hotel taxes has been effective where the level of effectiveness of hotel Taxes has reached the effectiveness criteria.
\end{abstract}

Keywords: PAD, Potency, Effectiveness

\section{PENDAHULUAN}

Pajak merupakan salah satu sumber dari sekian banyak sumber penerimaan pemerintah daerah yang digunakan untuk membiayai pembangunan di daerah yang bertujuan untuk dapat membiayai dan memajukan daerah yang ditempuh dengan kebijakan pada pengoptimalisasian penerimaan pajak, di mana setian orang wajib membayar pajak sesuai dengan kewajibannya.

Salah satu pajak daerah yang potensinya semakin berkembang seiring dengan semakin diperhatikannya komponen sektor jasa dan pariwisata dalam kebijakan pembangunan sehingga dapat menunjang berkembangnya bisnis rekreasi (pariwisata) adalah pajak hotel. Pariwisata dan hotel merupakan dua sektor yang potensial di Kabupaten Tana Toraja.Di mana Tana Toraja merupakan daerah dengan objek wisata dan budaya yang unik, yang dapat membuat Tana Toraja menjadi salah satu daerah di Sulawesi Selatan yang wajib dikunjungi. Dengan banyaknya wisatawan yang datang untuk berkunjung, maka akan mempengaruhi tingkat hunian hotel yang ada di Tana Toraja. Sehingga dengan adanya potensi sumber daya yang tersedia diharapkan kontribusi yang diberikan oleh sektor pariwisata dan hotel, khususnya hotel dapat mamacu pembangunan ekonomi di Kabupaten Tana Toraja.

Tabel 1.Target dan Realisasi Pajak Hotel Kabupaten Tana Toraja Tahun 2011-2015

\begin{tabular}{ccc}
\hline \multirow{2}{*}{ Tahun } & \multicolumn{3}{c}{ Pajak Hotel } \\
\cline { 2 - 3 } & Target (Rp) & Realisasi (Rp) \\
2011 & $78,100,000$ & $121,664,386$ \\
2012 & $78,100,000$ & $106,886,609$ \\
2013 & $78,100,000$ & $167,394,118$ \\
2014 & $119,110,000$ & $219,814,837$ \\
2015 & $83,454,000$ & $333,481,643$ \\
\hline
\end{tabular}

Sumber : DISPENDA 
Dari Tabel 1.1 menunjukkan bahwa target yang ditetapkan dari tahun 2011-2013 tidak mengalami perubahan, walaupun pada tahun 2014 mengalami peningkatan tetapi pada tahun 2015 target yang ditetapkan lebih rendah dari tahun sebelumnya, padahal realisasi pajak hotel dari tahun 2012-2015 mengalami peningkatan yang cukup besar. Adanya perbedaan besar antara target dan realisasi pemungutan pajak hotel menunjukkan adanya potensi pajak hotel yang belum digali secara maksimal. Dengan demikian pajak hotel di Kabupaten Tana Toraja sebenarnya memiliki potensi yang besar dibanding dengan target yang ditetapkan dan realisasi penerimaan pajak hotel, dilihat dari sektor pariwisata Tana Toraja yang semakin berkembang dari tahun ke tahun. Oleh sebab itu penulis merasa tertarik untuk meneliti permasalahan dengan judul "Analisis Potensi, Efektifitas dan Kontribusi Pajak Hotel terhadap Pendapatan Asli Daerah Kabupaten Tana Toraja”. Terkait masalah diatas maka tujuan penelitian ini adalah untuk menghitung besar potensi, efektifitas, dan kontribusi Pajak Hotel terhadap Pendapatan Asli Daerah Kabupaten Tana Toraja.

\section{TINJAUAN PUSTAKA Konsep Akuntansi}

Priyati (2013: 1) mengatakan bahwa Akuntansi adalah suatu kegiatan jasa, fungsinya adalah menyediakan data kuantitatif, terutama yang mempunyai sifat dari kesatuan usaha ekonomi yang dapat digunakan dalam pengambilan keputusan-keputusan dalam memilih alternatif-alternatif dari suatu keadaan atau dapat dikatakan: Akuntansi adalah proses pencatatan, penggolongan, peringkasan dan penyajian secara sistematis dari transaksitransaksi keuangan suatu badan usaha, serta penafsiran terhadap hasilnya.

\section{Konsep Pajak}

Pajak adalah iuran kepada negara (yang dapat dipaksakan) yang terutang oleh yang wajib membayarnya menurut peraturan-peraturan, dengan tidak mendapat prestasi kembali, yang langsung dapat ditunjuk, dan yang gunanya adalah untuk membiayai pengeluaranpengeluaran umum berhubung dengan tugas negara yang menyelenggarakan pemerintahan. (Waluyo,2011:2).

\section{Fungsi Pajak}

Sebagaimana telah diketahui unsur-unsur yang melekat pada pengertian pajak dari berbagai definisi, ada dua fungsi pajak (Waluyo, 2011: 6), yaitu :

1. Fungsi Penerimaan (Budgetary) yaitu pajak yang berfungsi sebagai sumber dana yang diperuntukkan bagi pembiayaan pengeluaran-pengeluaran pemerintah.

2. Fungsi Mengatur (Reguler) yaitu pajak berfungsi sebagai alat untuk mengatur atau melaksanakan kebijakan di bidang sosial dan ekonomi.

\section{Pendapatan Asli Daerah}

Pendapatan Asli Daerah (PAD) merupakan suatu pendapatan yang menunjukkan kemampuan suatu daerah dalam menghimpun sumber-sumber dana untuk membiayai pengeluaran rutin. Jadi, dapat dikatakan bahwa Pendapatan Asli Daerah sebagai pendapatan rutin dari usaha-usaha Pemerintah Daerah dalam memanfaatkan potensi-potensi sumber keuangan daerahnya sehingga dapat mendukung pembiayaan penyelenggaraan dan pembangunan daerah. PAD adalah pendapatan yang diperoleh daerah yang dipungut berdasarkan peraturan perundang-undangan. Sedangkan menurut Undang-Undang Nomor 33 Tahun 2004, sumber Pendapatan Asli Daerah meliputi : a) Retribusi Daerah, b) Hasil pengolahan kekayaan daerah yang dipisahkan, c) Lain-lain PAD yang sah, dan d) Pajak Daerah. 


\section{Pajak Daerah}

Pajak Daerah adalah pajak yang dipungut daerah berdasarkan peraturan pajak yang ditetapkan oleh daerah (melalui PERDA) untuk kepentingan pembiayaan rumah tangga tersebut. (Mardiasmo, 2011: 12). Menurut Undang-Undang No. 28 Tahun 2009 tentang Pajak Daerah dan Retribusi Daerah, "pajak daerah adalah kontribusi wajib kepada daerah yang terutang oleh orang pribadi atau badan yang bersifat memaksa berdasarkan Undang-Undang, dengan tidak mendapatkan imbalan secara langsung dan digunakan untuk keperluan daerah bagi sebesar-besarnya kemakmuran rakyat".

\section{Pajak Hotel}

Sesuai dengan Undang-Undang Nomor 28 Tahun 2009 Pasal 1 angka 20 dan 21, pajak hotel adalah pajak atas pelayanan yang disediakan oleh hotel. Sedangkan yang dimaksud dengan hotel adalah fasilitas penyedia jasa penginapan/peristirahatan termasuk jasa terkait lainnya dengan dipungut bayaran, yang mencakup juga motel, losmen, gubuk pariwisata, pesanggrahan, rumah penginapan dan sejenisnya, serta rumah kos dengan jumlah kamar lebih dari sepuluh. Pengenaan pajak hotel tidak mutlak ada pada seluruh daerah kabupaten atau kota yang ada di Indonesia (Siahaan, 2010: 299).

\section{Potensi Pajak Hotel}

Menurut Prakosa (2010: 42), potensi adalah kemampuan dari diri seseorang atau hal lain yang dapat digali atau bahkan dikembangkan. Adapun perhitungan potensi pajak hotel dilakukan dengan cara mengalikan rata-rata hunian kamar dengan tarif kamar rata-rata kemudian dikalikan dengan jumlah hari dalam satu tahun dan dikalikan dengan tarif pajak hotel (Mahmudi, 2009).

Untuk menghitung potensi Pajak Hotel digunakan rumus sebagai berikut:

$\mathrm{PPH}=\mathrm{A} \times \mathrm{B} \times \mathrm{C} \times \mathrm{D}$

\section{Efektifitas Pajak Hotel}

Efektifitas adalah suatu keadaan yang terjadi sebagai akibat yang dikehendaki. Adapun rumus untuk mengukur efektifitas yang terkait dengan perpajakan dalam Halim (2012: 168) adalah sebagai berikut:

\section{Efektifitas $=$}

\section{Kontribusi Pajak Hotel}

Menurut Kamus Ekonomi, kontribusi adalah sesuatu yang diberikan bersama-sama dengan pihak lain untuk tujuan biaya atau kerugian tertentu atau bersama. Dalam Halim (2012: 167) untuk menghitung tingkat kontribusi digunakan rumus sebagai berikut :

Kontribusi $=-$

\section{Penelitian Terdahulu}

1. Tesalonika(2016) dengan judul Analisis Potensi dan Efektifitas Penerimaan dan Pemungutan Pajak Mineral bukan Logam dan Batuan sebagai sumber Pendapatan Asli Daerah di Kabupaten Minahasa Utara. Metode penelitian yaitu deskriptif kualitatif. Dari hasil penelitian menunjukkan bahwa potensi pajak mineral bukan logam dan batuan menunjukkan hasil sebesar Rp. 4.280.437.530, dengan presentasi rata-rata kenaikan sebesar $15.35 \%$.

2. Sari (2013) dengan judul Analisis Kontribusi Pajak Hotel terhadap Pendapatan Asli Daerah di Kota Semarang. Metode yang digunakan adalah metode kuantitatif. Hasil penelitian didapatkan bahwa penerimaan Pajak Hotel Kota Semarang pada tahun 
2010-2012 memenuhi target setiap tahunnya, akan tetapi pertumbuhan pajak hotel di kota semarang mengalami penurunan dari $23.36 \%$ pada tahun 2010 menjadi $11.42 \%$ pada tahun 2012 .

\section{METODE PENELITIAN Jenis Penelitian}

Jenis penelitian ini adalah penelitian deskriptif, yaitu penelitian yang disusun dalam rangka memberikan gambaran secara sistematis tentang informasi ilmiah yang berasal dari subjek atau objek penelitian yang berfokus pada penjelasan sistematis tentang fakta yang diperoleh saat penelitian dilakukan (Sanusi, 2011:13).

\section{Tempat dan Waktu Penelitian}

Penelitian ini berlokasi di Kantor Dinas Pendapatan Daerah kabupaten Tana Toraja, Sulawesi Selatan. Waktu penelitian dilakukan pada bulan Juli 2016.

\section{Metode Pengumpulan Data}

Data yang digunakan dalam penelitian ini adalah data primer.Data primer atau data pokok ini adalah data yang diperoleh penulis dengan terjun langsung ke objek penelitian dalam hal ini melakukan wawancara dengan salah satu Pegawai Dinas Pendapatan Daerah Kabapaten Tana Toraja. Data sekunder adalah data yang diambil dari catatan atau sumber lain yang telah ada sudah diolah oleh pihak ketiga. Dalam penelitian ini data sekunder yang dikumpulkan adalah data realisasi dan target penerimaan Pajak Hotel, data Pajak Daerah, dan data Pendapatan Asli Daerah.

\section{Metode Analisis}

Metode analisis data yang digunakan dalam penelitian ini adalah analisis deskriptif. Langkahlangkah dalam menganalisis data tersebut adalah sebagai berikut:

1. Potensi Pajak Hotel

$$
\mathrm{PPH}=\mathrm{A} \times \mathrm{B} \times \mathrm{C} \times \mathrm{D}
$$

2. Efektifitas Pajak Hotel

Efektifitas =

3. Kontribusi Pajak Hotel

$$
\text { Kontribusi = - }
$$

4. Laju Pertumbuhan Pajak Hotel

\section{HASIL PENELITIAN DAN PEMBAHASAN \\ Gambaran Umum Objek Penelitian}

Kabupaten Tana Toraja yang beribukota Makale terletak antara $2^{\circ}-3^{\circ}$ Lintang Selatan dan $119^{\circ}-120^{\circ}$ Bujur Timur yang berbatasan dengan :

Di Sebelah Utara : Kabupaten Toraja Utara dan Kabupaten Mamuju

Di Sebelah Selatan : Kabupaten Enrekang dan Kabupaten Pinrang

Di Sebelah Timur : Kabupaten Luwu dan Kabupaten Luwu Utara

Di Sebelah Barat : Provinsi Sulawesi Barat

Kabupaten Tana Toraja dilewati oleh salah satu sungai terpanjang yang terdapat di Provinsi Sulawesi Selatan yaitu Sungai Saddang, dengan alirannya terdiri dari beberapa anak sungai antara lain sungai Mai'ting, Sapan Deata, Torin, dan Malea. 


\section{Hasil Penelitian dan Pembahasan}

Pendapatan Asli Daerah merupakan salah satu sumber pendapatan daerah yang memiliki peranan penting dalam pembangunan suatu daerah. Untuk mengetahui sejauh mana Pemerintah Daerah Kabupaten Tana Toraja dalam mengolah sumber Pendapatan Asli Daerah dalam menunjang plaksanaan pembangunan dan pemerintahan Kabupaten Tana Toraja

Tabel 2.Target dan Realisasi Pendapatan Pajak Hotel dan Pajak Daerah Kabupaten Tana Toraja Tahun 2011-2015

\begin{tabular}{ccccc}
\hline \multirow{2}{*}{ Tahun } & \multicolumn{2}{c}{ Pajak Hotel } & \multicolumn{2}{c}{ Pajak Daerah } \\
\cline { 2 - 5 } & Target $(\mathrm{Rp})$ & Realisasi (Rp) & Target (Rp) & Realisasi (Rp) \\
\hline 2011 & $78,100,000$ & $121,664,386$ & $2,141,100,000$ & $2,356,018,513$ \\
2012 & $78,100,000$ & $106,886,609$ & $2,348,050,000$ & $3,736,529,606$ \\
2013 & $78,100,000$ & $167,394,118$ & $2,398,050,000$ & $3,882,204,835$ \\
2014 & $119,110,000$ & $219,814,837$ & $5,057,372,000$ & $6,516,318,116$ \\
2015 & $83,454,000$ & $333,481,643$ & $4,980,454,000$ & $7,392,079,442$ \\
\hline
\end{tabular}

\section{Sumber : Dispenda Tana Toraja, 2016}

Dari Tabel 4.2 dapat dilihat bahwa target realisasi pajak hotel dari tahun $2012 \mathrm{ke}$ tahun 2015 terus mengalami peningkatan, begitu juga dengan realisasi Pajak Daerah. Ini menunjukkan bahwa target Pajak Hotel dan Pajak Daerah pada tahun 2011- 2015 telah tercapai.

\section{Perhitungan Potensi Penerimaan Pajak Hotel}

Dalam menghitung potensi pajak ada beberapa komponen yang harus dicermati antara lain sebagai berikut
a. Jenis kamar
b. Jumlah Kamar
c. Tingkat Hunian
d. Tarif rata-rata kamar

Berikut disajikan jenis hotel dan jumlah hotel yang ada di kabupaten Tana Toraja selama tahun 2011-2015

Tabel 3.Jumlah Hotel dan Jumlah Kamar Hotel di Kabupaten Tana Toraja Tahun 2011-2015

\begin{tabular}{llll}
\hline No. & Jenis Hotel & Jumlah Hotel & Jumlah Kamar \\
\hline 1 & Bintang Tiga & 1 & 52 \\
2 & Bintang Dua & 2 & 31 \\
3 & Melati Tiga & 2 & 161 \\
4 & Melati Dua & 4 & 41 \\
5 & Melati Satu & 2 & 44 \\
\hline
\end{tabular}

Sumber : DISPENDA Tana Toraja, 2016

Dari Tabel 4.3 dapat dilihat bahwa jumlah hotel yang ada di Kabupaten Tana Toraja jumlah masih terbilang sedikit dan jumlah hotel serta jumah kamar tidak mengalami peningkatan dari tahun ke tahun.Namun tidak menutup kemungkinan bahwa jumlah penerimaan Pajak Hotel dari tahun ke tahun terus meningkat. 
Tabel 4.Rata-rata Tarif Kamar dan Tingkat Hunian Kamar tahun 2011-2015

\begin{tabular}{lccccccccccc}
\hline \multirow{2}{*}{$\begin{array}{c}\text { Jenis } \\
\text { Hotel }\end{array}$} & \multicolumn{2}{c}{2011} & \multicolumn{1}{c}{2012} & \multicolumn{2}{c}{2013} & \multicolumn{2}{c}{2014} & \multicolumn{2}{c}{2015} \\
\hline Karif & TH & $\begin{array}{c}\text { Tarif } \\
\text { Kamar }\end{array}$ & TH & $\begin{array}{c}\text { Tarif } \\
\text { Kamar }\end{array}$ & TH & $\begin{array}{c}\text { Tarif } \\
\text { Kamar }\end{array}$ & TH & $\begin{array}{c}\text { Tarif } \\
\text { Kamar }\end{array}$ & TH \\
\hline $\begin{array}{l}\text { Bintang } \\
\text { Tiga }\end{array}$ & 450,000 & 0.24 & 450,000 & 0.21 & 450,000 & 0.36 & 450,000 & 0.43 & 450,000 & 0.61 \\
$\begin{array}{l}\text { Bintang } \\
\text { Dua }\end{array}$ & 180,000 & 0.24 & 180,000 & 0.41 & 180,000 & 0.5 & 180,000 & 0.69 & 180,000 & 0.83 \\
$\begin{array}{l}\text { Melati } \\
\text { Tiga }\end{array}$ & 100,000 & 0.19 & 100,000 & 0.22 & 100,000 & 0.26 & 100,000 & 0.49 & 100,000 & 0.8 \\
$\begin{array}{l}\text { Melati } \\
\text { Dua }\end{array}$ & 75,000 & 0.06 & 75,000 & 0.28 & 75,000 & 0.68 & 75,000 & 0.65 & 75,000 & 0.39 \\
$\begin{array}{l}\text { Melati } \\
\text { Satu }\end{array}$ & 60,000 & 0.07 & 60,000 & 0.17 & 60,000 & 0.3 & 60,000 & 0.33 & 60,000 & 0.4 \\
\hline
\end{tabular}

\section{Sumber : DISPENDA Tana Toraja, data diolah}

Dari kedua tabel di atas menggunakan asumsi bahwa :

a. Jumlah hari dalam satu tahun : 360 hari

b. Masa hunian kamar : 1 x 1 hari

c. Tarif kamar per malam berdasarkan rata-rata

Berdasarkan perhitungan potensi pajak dan tarif rata-rata yang ada serta beberapa asumsi yang digunakan, maka dapat dihitung besarnya potensi Pajak Hotel yang ada di Kabupaten Tana Toraja Tahun 2011-2015, sebagai berikut :

Tabel 5.Perhitungan Potensi Pajak Hotel Kabupaten Tana Toraja Tahun 2011

\begin{tabular}{cccccc}
\hline $\begin{array}{c}\text { Klasifikasi } \\
\text { Hotel }\end{array}$ & $\begin{array}{c}\text { Jumlah } \\
\text { Kamar }\end{array}$ & $\begin{array}{c}\text { Tarif } \\
\text { Kamar }\end{array}$ & $\begin{array}{c}\text { Tingkat } \\
\text { Hunian }\end{array}$ & $\begin{array}{c}\text { Jumlah } \\
\text { Hari }\end{array}$ & Omzet/Tahun \\
\hline Bintang Tiga & 52 & 450,000 & 0.24 & 360 & $2,021,760,000$ \\
Bintang Dua & 31 & 180,000 & 0.24 & 360 & $482,112,000$ \\
Melati Tiga & 161 & 100,000 & 0.19 & 360 & $1,101,240,000$ \\
Melati Dua & 41 & 75,000 & 0.06 & 360 & $66,420,000$ \\
Melati Satu & 44 & 60,000 & 0.07 & 360 & $66,528,000$ \\
\cline { 2 - 2 } & 329 & & & & $3,738,060,000$ \\
\hline
\end{tabular}

Sumber : Data primer dan sekunder diolah, 2016

Tabel 6.Perhitungan Potensi Pajak Hotel Kabupaten Tana Toraja Tahun 2012

\begin{tabular}{cccccc}
\hline $\begin{array}{c}\text { Klasifikasi } \\
\text { Hotel }\end{array}$ & $\begin{array}{c}\text { Jumlah } \\
\text { Kamar }\end{array}$ & $\begin{array}{c}\text { Tarif } \\
\text { Kamar }\end{array}$ & $\begin{array}{c}\text { Tingkat } \\
\text { Hunian }\end{array}$ & $\begin{array}{c}\text { Jumlah } \\
\text { Hari }\end{array}$ & \multirow{2}{*}{ Omzet/Tahun } \\
\hline Bintang Tiga & 52 & 450,000 & 0.21 & 360 & $1,769,040,000$ \\
Bintang Dua & 31 & 180,000 & 0.41 & 360 & $823,608,000$ \\
Melati Tiga & 161 & 100,000 & 0.22 & 360 & $1,275,120,000$ \\
Melati Dua & 41 & 75,000 & 0.28 & 360 & $309,960,000$ \\
Melati Satu & 44 & 60,000 & 0.17 & 360 & $161,568,000$ \\
\cline { 2 - 2 } & 329 & & & & $4,339,296,000$ \\
\hline
\end{tabular}

Sumber : Data primer dan sekunder diolah, 2016 
Tabel 7.Perhitungan Potensi Pajak Hotel Kabupaten Tana Toraja Tahun 2013

\begin{tabular}{llllll}
\hline Klasifikasi & Jumlah & Tarif Kamar & $\begin{array}{l}\text { Tingkat } \\
\text { Hunian }\end{array}$ & Jumlah Hari & Omzet/Tahun \\
\hline Bintang Tiga & 52 & 450,000 & 0.36 & 360 & $3,032,640,000$ \\
Bintang Dua & 31 & 180,000 & 0.5 & 360 & $1,004,400,000$ \\
Melati Tiga & 161 & 100,000 & 0.26 & 360 & $1,506,960,000$ \\
Melati Dua & 41 & 75,000 & 0.68 & 360 & $752,760,000$ \\
Melati Satu & 44 & 60,000 & 0.3 & 360 & 285,120,000 \\
\cline { 2 - 6 } & 329 & & & & $6,581,880,000$ \\
\hline
\end{tabular}

Sumber : Data primer dan sekunder diolah, 2016

Tabel 8.Perhitungan Potensi Pajak Hotel Kabupaten Tana Toraja Tahun 2014

\begin{tabular}{cccccc}
\hline $\begin{array}{c}\text { Klasifikasi } \\
\text { Hotel }\end{array}$ & $\begin{array}{c}\text { Jumlah } \\
\text { Kamar }\end{array}$ & Tarif Kamar & $\begin{array}{c}\text { Tingkat } \\
\text { Hunian }\end{array}$ & Jumlah Hari & Omzet/Tahun \\
\hline Bintang Tiga & 52 & 450,000 & 0.43 & 360 & $3,622,320,000$ \\
Bintang Dua & 31 & 180,000 & 0.69 & 360 & $1,386,072,000$ \\
Melati Tiga & 161 & 100,000 & 0.49 & 360 & $2,840,040,000$ \\
Melati Dua & 41 & 75,000 & 0.65 & 360 & $719,550,000$ \\
Melati Satu & 44 & 60,000 & 0.33 & 360 & $313,632,000$ \\
\cline { 2 - 4 } & 329 & & & & $8,881,614,000$ \\
\hline
\end{tabular}

Sumber : Data primer dan sekunder diolah, 2016

Tabel 9.Perhitungan Potensi Pajak Hotel Kabupaten Tana Toraja Tahun 2015

\begin{tabular}{ccclcc}
\hline $\begin{array}{c}\text { Klasifikasi } \\
\text { Hotel }\end{array}$ & $\begin{array}{c}\text { Jumlah } \\
\text { Kamar }\end{array}$ & Tarif Kamar & $\begin{array}{c}\text { Tingkat } \\
\text { Hunian }\end{array}$ & Jumlah Hari & Omzet/Tahun \\
\hline Bintang Tiga & 52 & 450,000 & 0.61 & 360 & $5,138,640,000$ \\
Bintang Dua & 31 & 180,000 & 0.83 & 360 & $1,667,304,000$ \\
Melati Tiga & 161 & 100,000 & 0.8 & 360 & $4,636,800,000$ \\
Melati Dua & 41 & 75,000 & 0.39 & 360 & $431,730,000$ \\
Melati Satu & 44 & 60,000 & 0.4 & 360 & $380,160,000$ \\
\cline { 2 - 5 } & & & & & $12,254,634,000$ \\
\hline
\end{tabular}

Sumber : Data primer dan sekunder diolah, 2016

Berdasarkan hasil perhitungan potensi Pajak Hotel pada hasil penelitian selama 5 periode maka total omzet yang dihasilkan dikalikan dengan tarif pajak sebesar $10 \%$ sehingga didapatkan hasil dari penerimaan potensi Pajak Hotel, berikut disajikan total penerimaan potensi Pajak Hotel, yaitu :

Tabel 10.Potensi Pajak Hotel Kabupaten Tana Toraja Tahun 2011-2015

\begin{tabular}{lll}
\hline Tahun & Potensi Pajak Hotel $(\mathrm{Rp})$ & Perubahan $(\mathrm{Rp})$ \\
\hline 2011 & $373,806,000$ & - \\
2012 & $433,292,600$ & $59,486,600$ \\
2013 & $658,188,600$ & $224,896,000$ \\
2014 & $888,161,400$ & $229,972,800$ \\
2015 & $1,225,463,400$ & $337,302,000$ \\
\hline
\end{tabular}

Sumber : Data diolah, 2016 
Dari Tabel 4.11 dapat diketahui bahwa potensi pajak hotel dari tahun ke tahun mengalami peningkatan. Pada tahun 2011 total penerimaan potensi Pajak Hotel sebesar Rp. 373,806,000 dan mengalami peningkatan sebesar Rp. 59,486,600 dengan jumlah penerimaan potensi Pajak Hotel pada tahun 2012 sebesar Rp. 433,292,600. Pada tahun 2013 jumlah penerimaan potensi Pajak Hotel Rp. 658,188,600 dengan jumlah peningkatan sebesar Rp. 224,896,000 dari tahun sebelumnya. Begitu pula pada tahun 2014 dan 2015 yang terus mengalami peningkatan dengan jumlah masing-masing potensi sebesar Rp. 888,161,400 pada tahun 2014 dan Rp. 1,225,463,400 pada tahun 2015. Peningkatan penerimaan Potensi Pajak Hotel dipengaruhi oleh bertambahnya jumlah tingkat hunian kamar hotel dari tahun ke tahun.

\section{Efektifitas Pajak Hotel}

Berikut perhitungan efektifitas pajak hotel dari tahun 2011 sampai tahun 2015 :

Tabel 11.Efektifitas Pajak Hotel Kabupaten Tana Toraja Tahun 2011-2015

\begin{tabular}{lllll}
\hline Tahun & Target $(\mathrm{Rp})$ & Realisasi $(\mathrm{Rp})$ & Presentase $\%$ & Kriteria \\
\hline 2011 & $78,100,000$ & $121,664,386$ & $155.78 \%$ & Sangat Efektif \\
2012 & $78,100,000$ & $106,886,609$ & $136.86 \%$ & Sangat Efektif \\
2013 & $78,100,000$ & $167,394,118$ & $214.33 \%$ & Sangat Efektif \\
2014 & $119,110,000$ & $219,814,837$ & $184.55 \%$ & Sangat Efektif \\
2015 & $83,454,000$ & $333,481,643$ & $399.60 \%$ & Sangat Efektif \\
\hline
\end{tabular}

Sumber : Data diolah, 2016

Dari Tabel 4.13 menunjukkan bahwa efektifitas pemungutan Pajak Hotel sudah efektif. Dimana tingkat efektifitas pada tahun mencapai $155.78 \%$, tahun 2012 mencapai $136.86 \%$, tahun 2013 mencapai $214.33 \%$, tahun 2014 mencapai $184.55 \%$, dan tahun 2015 mencapai $399.60 \%$.

\section{Kontribusi Pajak Hotel}

Untuk mengetahui seberapa besar kontribusi Pajak Hotel terhadap Pajak Daerah dan Pendapatan Asli Daerah maka disajikan data sebagai berikut :

Tabel 12.Kontribusi Pendapatan Pajak Hotel terhadap Pajak Daerah dan Pendapatan Asli Daerah Kabupaten Tana TorajaTahun 2011-2015

\begin{tabular}{cccccc}
\hline \multirow{2}{*}{$\begin{array}{c}\text { Tahu } \\
\text { n }\end{array}$} & $\begin{array}{c}\text { Pajak Hotel } \\
\text { (Rp) }\end{array}$ & $\begin{array}{c}\text { Pajak Daerah } \\
(\mathrm{Rp})\end{array}$ & $\begin{array}{c}\text { Pendapatan Asli Daerah } \\
(\mathrm{Rp})\end{array}$ & $\begin{array}{c}\text { Pajak Daerah } \\
(\%)\end{array}$ & $\begin{array}{c}\text { Pendapatan Asli } \\
\text { Daerah }(\%)\end{array}$ \\
\hline 2011 & $121,664,386$ & $2,356,018,513$ & $19,686,833,802$ & 5.16 & 0.62 \\
2012 & $106,886,609$ & $3,736,529,606$ & $31,720,677,572$ & 2.86 & 0.34 \\
2013 & $167,394,118$ & $3,882,204,835$ & $38,776,667,265$ & 4.31 & 0.43 \\
2014 & $219,814,837$ & $6,516,318,116$ & $82,506,082,709$ & 3.37 & 0.27 \\
2015 & $333,481,643$ & $7,392,079,443$ & $79,256,819,867$ & 4.51 & 0.42 \\
\hline
\end{tabular}

\section{Sumber : DISPENDA Tana Toraja, data olahan}

Berdasarkan Tabel 4.10 menunjukkan bahwa kontribusi Pajak Hotel Kabupaten Tana Toraja terhadap Pajak Daerah dan Pendapatan Asli Daerah masih sangat kurang, dimana kontribusi Pendapatan Asli Daerah berada di bawah 1\%. Kontribusi rata-rata Pajak Hotel terhadap Pendapatan Asli Daerah hanya sebesar $0.41 \%$. 


\section{KESIMPULAN DAN SARAN \\ Kesimpulan}

Berdasarkan hasil penelitian dan pembahasan tersebut, maka dapat diambil beberapa kesimpulan, antara lain :

1. Berdasarkan hasil perhitungan dari potensi penerimaan pajak hotel bahwa masih ada selisih yang besar antara potensi pajak hotel dengan realisasi penerimaan pajak hotel .

2. Penetapan target penerimaan pajak hotel yang ditetapkan oleh Pemerintah Daerah hanya didasarkan pada penerimaan tahun-tahun sebelumnya tanpa memperhitungkan potensi yang ada sehingga penggalian potensi pajak yang ada masih belum optimal.

3. Pelaksanaan pemungutan pajak hotel Kabupaten Tana Toraja sudah efektif, di mana tingkat efektifitas pajak hotel sudah mencapai kriteria efektifitas yaitu berada di atas $100 \%$.

4. Kontribusi pajak hotel terhadap Pendapatan Asli Daerah masih sangat kurang, ini menunjukkan bahwa kontribusi pajak hotel masih sangat sedikit dibandingkan pajak daerah lainnya.

\section{Saran}

Adapun saran yang dapat diberikan sebagai berikut :

1. Dengan melihat potensi yang ada diharapkan kepada Pemerintah Daerah Kabupaten Tana Toraja khususnya Dinas Pendapatan Daerah agar mengkaji ulang target yang ditetapkan agar sesuai dengan potensi yang sesungguhnya dari pajak hotel, karena target yang ditetapkan berbanding jauh dengan potensi pajak hotel.

2. Dalam penetapan target pemungutan pajak hotel, pemerintah diharapkan tidak hanya berpatokan pada target tahun-tahun sebelumnya tetapi juga memperhatikan potensi pajak hotel yang ada.

3. Untuk tetap menjaga efektifitas pemungutan pajak hotel Kabupaten Tana Toraja pemerintah perlu meningkatkan pengawasan dan memberikan sanksi administrasi kepada wajib pajak yang melakukan pelanggaran.

4. Untuk meningkatkan kotribusi pajak hotel terhadap PAD pemerintah perlu menggali lagi potensi yang ada agar mempengaruhi peningkatan penerimaan pajak hotel.

\section{DAFTAR PUSTAKA}

Halim, Abdul dan Muhammad Iqbal. 2012. Bunga Rampai Manajemen Keuangan Daerah: Pengelolaan Keungan Daerah. Edisi Revisi. Yogyakarta: UPP AMP YKPN.

Mahmudi,. 2009. Manajemen Keuangan Daerah. Jakarta: Erlangga.

Mardiasmo. 2011. Perpajakan. Edisi Revisi. Yogyakarta: Andi.

Prakosa, Kesit Bambang. 2010. Pajak dan Retribusi Daerah. Edisi Revisi. Yogyakarta: UII Press.

Priyati, Novi. 2011. Pengantar Akuntansi. PT. Indeks. Jakarta

Republik Indonesia. 2009. Undang-Undang No. 28 Tahun 2009 tentang Pajak Daerah dan Retribusi Daerah

Sanusi, Anwar. 2011. Metodologi Penelitian Bisnis. Jakarta : Salemba Empat.

Sari, Nadya T. 2013.Analisis Kontribusi Pajak Hotel terhadap Pendapatan Asli Daerah di Kota Semarang. Semarang: Universitas Dian Nuswaantoro Semarang.

Siahaan, Marihot P. 2010. Pajak Daerah dan Retribusi Daerah.Edisi Revisi. Jakarta : PT Raja Grafindo Persada.

Tesalonika, Moningka. 2016. Analisis Potensi dan Efektifitas Penerimaan dan Pemungutan Pajak Mineral bukan Logam dan Batuan sebagai sumber Pendapatan Asli Daerah di Kabupaten Minahasa Utara. Going Concern Unsrat Vol. 11 No. 3.

Waluyo. 2011. Perpajakan Indonesia. Jakarta: Salemba Empat. 